\title{
Tacit knowledge sharing in online environments: locating 'Ba' within a platform for public sector professionals
}

\section{Authors}

\author{
Iris Buunk, Colin F. Smith, Hazel Hall
}

School of Computing, Edinburgh Napier University, Scotland, UK

\section{Abstract}

Presented in this article are some findings from a study which investigates tacit knowledge sharing and social media use. The results reported here derive from a survey completed by members of an online platform that incorporates social media features, and enables information and knowledge sharing amongst public sector professionals. Two main findings emerge from the study. The first is that online social platforms play a strong role in in the facilitation of tacit knowledge sharing, and this leads to outcomes of learning, expertise sharing, problem solving, and innovating. The second is that the online platform is important to the initiation of discussions among experts, the fostering of collective intelligence, and making tacit and personal knowledge visible and accessible quickly, and with minimal effort. This work makes an important theoretical contribution by renewing consideration of the concept of $\mathrm{Ba}$ (Nonaka and Konno, 1998), and through the identification of Dialoguing/interacting $\mathrm{Ba}$ and Exercising $\mathrm{Ba}$ (in addition to Cyber Ba) in online environments.

\section{Keywords}

tacit knowledge, knowledge sharing, social media affordances, Ba, knowledge management, public sector

\section{Introduction}

The work reported here responds to earlier calls to enhance our understanding of information behaviour and knowledge sharing practices in online environments (for example, Widen-Wulff et al., 2008, p. 352). It has been argued that new knowledge in this area is important for the development of personal and organisational strategies 


\section{Buunk, I., Smith C.F., \& Hall, H. (2018 in press). Tacit knowledge sharing in online environments: locating 'Ba' within a platform for public sector professionals. Journal of Librarianship and Information Science.}

designed to support informal learning activities (Mills et al., 2014, p. 333). One of the main problems associated with such strategies is the perennial challenge posed by the transfer of tacit knowledge between individuals. The widespread adoption of social media technologies around, and increasingly within, the workplace adds a new dimension (and potentially a new solution) to this challenge.

Results from a survey completed by members of an online social platform that incorporates social media features are presented in this article. This survey was implemented as part of a larger study that investigates tacit knowledge sharing, online platforms, and social media use within the public sector in Scotland. These are themes which, to date, have been under-explored by researchers. The work reported here addresses one of the aims of the larger study by examining the extent to which social media afford new capabilities in the sharing of tacit knowledge.

Two main findings from the study are explored. Together they represent a distinct and significant contribution towards understandings of tacit knowledge sharing in online environments. The first is that online social interactions can facilitate the sharing of tacit knowledge as related to learning, expertise sharing, problem solving, and innovating. The second is that social interactions are facilitated by technological features of an online social platform. Importantly, this research also indicates that at least three elements of Nonaka and Konno's (1998) concept of Ba (or 'space') can be found within online environments. These are specific types of Ba: Dialoguing/Interacting Ba, Cyber Ba and Exercising $\mathrm{Ba}$.

\section{Contexts: the public sector, the concept of $\mathrm{Ba}$, and social media affordances}

\section{Knowledge sharing in the public sector}

There is scant literature that considers the themes of tacit knowledge sharing and online social platforms, especially in respect of the public sector. Massaro et al. (2015), for example, note that most studies of knowledge management practices focus on the private sector. They argue for the development of a distinct research agenda that takes full account of the specifics of the public sector context.

Social, economic and political factors all help shape the institutional norms of the public sector (Pettigrew, 2005), and the management of public services occurs in a complex policy and political environment, including direct political oversight and with high levels of scrutiny and accountability (Hartley and Skelcher, 2008). Unlike the private sector with its clear profit motive, the over-arching aim of the public sector is to add value through service delivery that maximises resource allocation, and the drivers for change in the public sector come from government policy rather than competitive pressures. However, decades of reform have seen governments push fundamental changes in the 


\section{Buunk, I., Smith C.F., \& Hall, H. (2018 in press). Tacit knowledge sharing in online environments: locating 'Ba' within a platform for public sector professionals. Journal of Librarianship and Information Science.}

leadership, management and organisation of public services in an attempt to achieve gains from the adoption of entrepreneurial and 'customer focused' approaches (Pettigrew, 2005). This has placed greater emphasis on the need for public sector professionals to share information and knowledge to foster learning and innovation, and to meet stakeholder expectations. Knowledge sharing, therefore, has been seen as crucial to public sector improvement, with wide recognition that good ideas and practices should not be limited to one organisation or service, but should be transferred across services, and between levels within organisations (Hartley, 2008). Despite this, relatively little attention has been paid to the means by which such knowledge transfer can occur (Rashman, Withers \& Hartley, 2009).

The approach taken here, focusing on the role of online platforms in tacit knowledge sharing in the public sector, aims to deepen the understanding of the domain, taking into consideration work from associated areas such as extant work on tacit knowledge sharing techniques such as communities of practice (Lave and Wenger, 1991). The theory of Ba (Nonaka and Konno, 1998), which identifies shared 'space' (physical, virtual or mental) as a foundation for knowledge creation, has clear relevance when considering the transmission of tacit knowledge. Further, the emergence of new affordances for knowledge sharing associated with social media brings an additional imperative to revisit foundational concepts, including Ba.

\section{The concept of $\mathrm{Ba}$}

Tacit knowledge is personal and highly contextual (Edmondson et al. 2003; Nonaka, 1994; Oguz and Sengün, 2011). Therefore, it is essential to investigate the variety of contexts within which tacit knowledge is shared. One of the developments of Nonaka's initial work concerns the introduction of the concept of Ba (Nonaka and Konno, 1998), understood as a contextual space that is shared with other people, and within which knowledge sharing, transfer, or mobilisation can occur. Knowledge is embedded within $\mathrm{Ba}$, and acquired by people as they gain experiences, or appreciate the experiences of others, in $\mathrm{Ba}$. The knowledge that resides within $\mathrm{Ba}$ is intangible (and knowledge that is separated from Ba becomes information, to be codified and communicated in tangible form). The shared spaces of Ba may be physical and/or virtual, and/or mental. Four types of Ba were originally defined by Nonaka and Konno (1998):

(1) Originating Ba is an 'existential' place in which individuals can share experiences, emotions, feelings and ideas face-to-face through a process of socialisation. Here barriers between the self and others are diminished, and organisational culture is implicitly communicated. This is 'primary' $\mathrm{Ba}$, where the initiation of the knowledge creation process takes place through direct encounters between people.

(2) Dialoguing/Interacting Ba is more consciously constructed than Originating Ba, through the assembly of participants, for example in team or project work. This is space in which knowledge, skills and mental models are shared among peers through an externalisation process, and where tacit knowledge in converted to explicit. Dialogue is 
Buunk, I., Smith C.F., \& Hall, H. (2018 in press). Tacit knowledge sharing in online environments: locating 'Ba' within a platform for public sector professionals. Journal of Librarianship and Information Science.

crucial in this process as individuals consider their own knowledge, skills and mental models alongside that of others.

(3) Cyber Ba (also known as 'Systemizing Ba') is a virtual space in which explicit knowledge is shared and combined in systematic ways. Technologies such as online networks, groupware and databases provide collaborative environments suitable for the facilitation of this information and knowledge sharing.

(4) Exercising Ba is a space where new knowledge is absorbed through an internalisation process. During this, explicit knowledge is converted into tacit knowledge. Unlike Dialoguing/Interacting Ba (which emphasises knowledge sharing through thought), Exercising Ba emphasises action and learning-by-doing. Here, individuals use the explicit knowledge made available to them to translate knowledge into action.

Ba thus provides a platform and is a foundation for knowledge creation (Nonaka and Konno, 1998) where the conversion of tacit to explicit knowledge can occur.

This knowledge conversion process may also be understood through the consideration of the Socialisation-Externalisation-Combination-Internalisation (SECI) model (Nonaka, 1994). This is a dynamic representation of the sharing, use and conversion of knowledge between individuals, within a group, or across an organisation. Each of the four stages is supported by Ba, as shown in Figure 1. The SECI model highlights that the knowledge conversion process between tacit and explicit knowledge brings the opportunity to learn new knowledge. Learning occurs by way of an internalisation process. This aligns with Exercising Ba as new knowledge is absorbed.

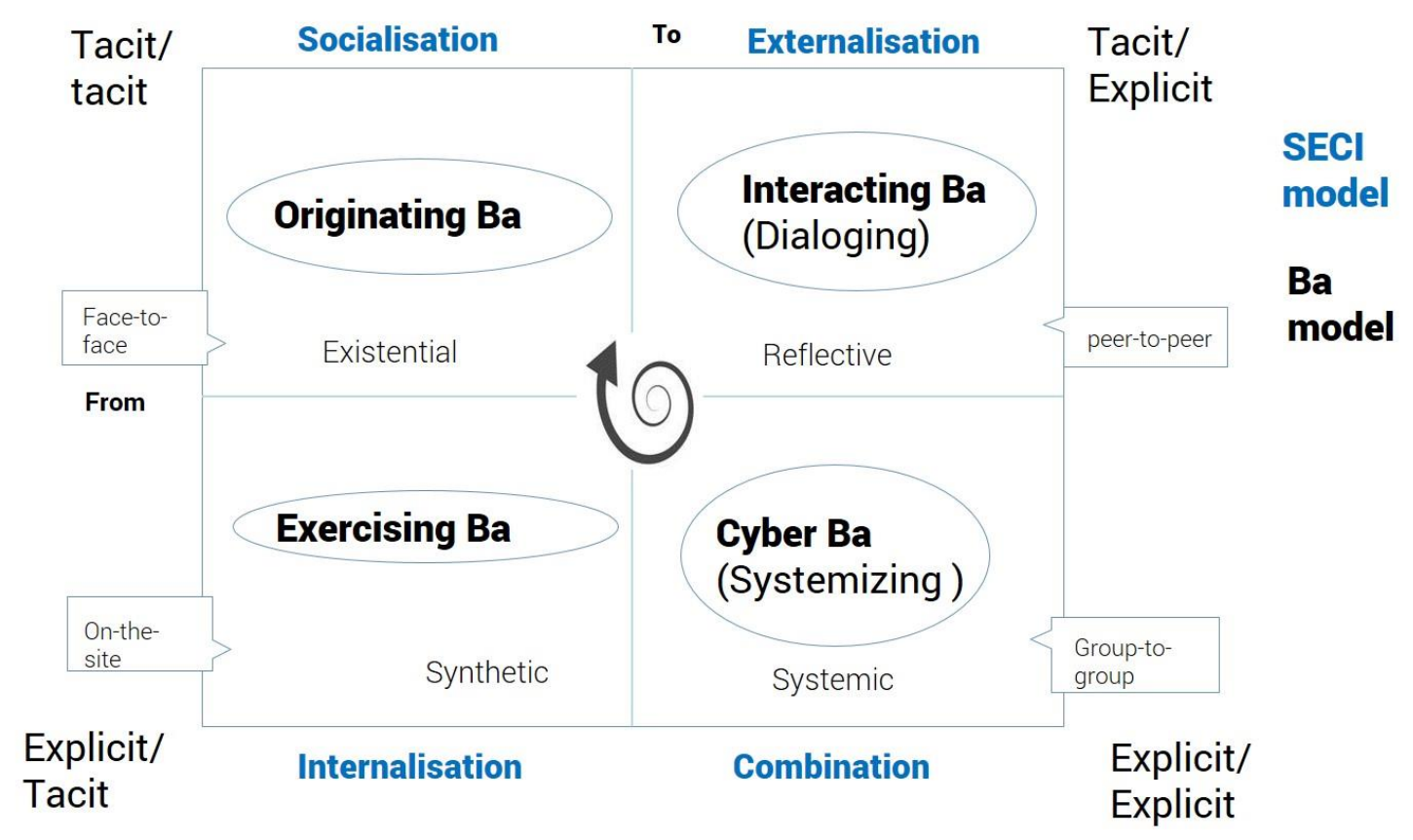

Figure 1 The Ba and SECI model (Nonaka and Konno, 1998) 
The dynamism generated by this knowledge conversion process has also been explained by Nonaka (1994) in a different, and often overlooked, model named the 'Spiral model of knowledge creation', as shown in Figure 2. Using the spiral metaphor, this model illustrates the dynamic interplay between tacit and explicit knowledge during the four stages of knowledge conversion. The model emphasises a continuous movement of knowledge creation, where knowledge grows at pace as more employees participate in the process until the entire organisation is involved.

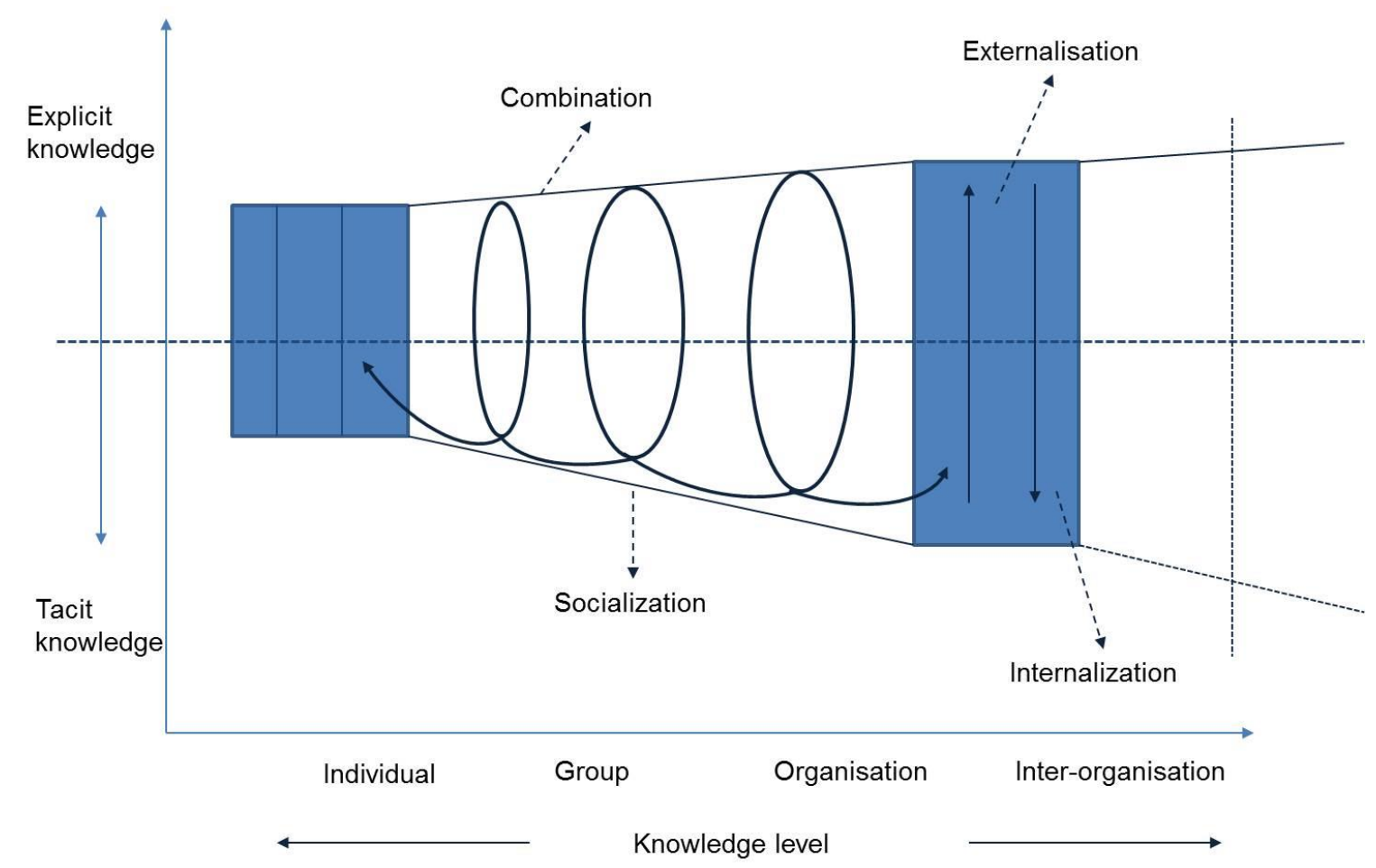

Figure 2 Spiral of organisational knowledge creation (Nonaka, 1994)

The concept of Ba originated in Japan. As such, it can be a challenging concept for those in the West (Nakanori, 2006; Zhu, 2006). A further issue is that an understanding of the subtleties of $\mathrm{Ba}$ is compounded by difficulties in its explicit translation from Japanese into other languages, including English. A resulting lack of shared scholarly understanding of Ba could therefore be considered a weakness. Alternatively, however, it has been suggested that this allows for various interpretations of $\mathrm{Ba}$ without compromising its depth and versatility (Nakanori, 2006). Difficulties and ambiguities in comprehending $\mathrm{Ba}$ are both important and useful, because they bring into perspective a number of criticisms that have allowed for subsequent revisions of it to be proposed and adopted.

Thus several scholars have analysed and revisited Nonaka's theories since the publication of his work on Ba and SECI in the 1990s, as cited above. Some have been critical, while 


\section{Buunk, I., Smith C.F., \& Hall, H. (2018 in press). Tacit knowledge sharing in online environments: locating 'Ba' within a platform for public sector professionals. Journal of Librarianship and Information Science.}

others have suggested updates to the original ideas, particularly in respect of the affordances of new technologies that have recently become available.

Most criticism concerns the SECI model (as noted by Choo and Alvarenga, 2010). Few scholars have criticised Ba per se. However, amongst these is Zhu (2006). For example, he is critical of Nonaka and Toyoma (2003) for drawing upon Structuration Theory (Giddens, 1984) to further justify Ba. He also considers the concept as overly simplistic and optimistic, arguing that it does not take into consideration the complexity of human beings, nor the challenges to knowledge management that are well documented elsewhere in the literature, such as barriers to knowledge sharing, including power dimensions (see, for example, Ardichvili, 2008; Goody and Hall, 2007; Hubert and Lopez, 2013; Mcdermott and O'Dell, 2001; Rosen et al., 2007). At the same time Zhu (2006) acknowledges that his full understanding of Ba may in fact be limited due to a lack of shared cultural perspectives. This illustrates the point articulated by Nakanori (2006), as mentioned above.

\section{Revisiting $\mathrm{Ba}$ in the context of social media}

It has been proposed that social media platforms share similarities with $\mathrm{Ba}$ in that they represent a space or 'place' (Razmerita et al., 2014) in which social interactions are enabled (Panahi et al., 2013). This has led to suggestions that tacit knowledge can now be shared online thanks to the specific affordances of social media. Two studies that support this contention are discussed below.

First, Martin-Niemi and Greatbanks (2010) analysed the extent to which the characteristics of a blog community could be related to the enabling conditions of knowledge conversion. In doing so they drew upon the SECI model (Nonaka, 1994) and $\mathrm{Ba}$ (Nonaka and Konno, 1998). They deployed a digital ethnographic approach using observation and analysis of the conversations that occurred within the blog community over a period of five months. This revealed ten enabling conditions for the conversion of tacit knowledge between individuals. Amongst these were enculturation and a sense of community within virtual environments. The sense of community drew upon prior work which identified four elements as important: membership; influence; integration and fulfilment (reinforcement) of needs; and shared emotional connection (McMillan and Chavis, 1986). The challenges that employees may face when they are dispersed throughout different geographic locations, and cannot have face-to-face contact and interactions, were also addressed in this study. The findings suggested that since social media tools enable 'person-to-person' interactions, face-to-face interactions may not be necessary (Martin-Niemi and Greatbanks, 2010: p.20). This led to the conclusion that the conversion of tacit knowledge between individuals can occur within a virtual context, and this relates to both Originating $\mathrm{Ba}$ and Dialoguing/interacting $\mathrm{Ba}$.

The second example of prior work of relevance here is a study based upon a European project named Business Innovation in Virtual Enterprise Environments (BIVEE). The 


\section{Buunk, I., Smith C.F., \& Hall, H. (2018 in press). Tacit knowledge sharing in online environments: locating 'Ba' within a platform for public sector professionals. Journal of Librarianship and Information Science.}

aim of BIVEE was to evaluate the applicability of the SECI model in a virtual community of practice (Bartolacci et al, 2016). The study allowed for the examination of a collaborative platform that was created to support members of virtual communities of practice in knowledge sharing for the purpose of fostering innovation. The platform included virtual tools such as instant messaging, forums and meeting rooms. These made it possible for professionals to 'meet' together to share ideas while 'seeing' one another (although, unfortunately, the specific type of visual tool used is not defined). Several relevant outcomes are emphasised in the study. First, each phase of the SECI model can occur online, including the Socialisation process, during which sharing intuition and ideas takes place, on the condition that rich media tools are present to support social interactions. A second related outcome is that Cyber $\mathrm{Ba}$ is not limited to the sharing of explicit knowledge alone. This is argued on the basis that all elements apparent in the SECI model can occur online. Further, since the socialisation process can now occur through virtual social interactions, it is asserted that face-to-face interactions and physical proximity are no longer necessary conditions for Originating $\mathrm{Ba}$. These findings build on others presented in studies in the field of online education (for instance, Levenberg and Caspi, 2010) that also indicate that rich media communication, or online conference tools such as Skype or WebEx, might facilitate the sharing of tacit knowledge in virtual environments. Here too it is shown that when technology enables face-to-face interactions, these occur within Originating Ba.

These empirical studies contribute to a greater understanding of social media affordances in the sharing of tacit knowledge. They also provide necessary revisions of the concept of $\mathrm{Ba}$, particularly with in respect of the emergence of new social technologies. However, the conclusions drawn by Martin-Niemi and Greatbanks (2010) and Bartolacci et al. (2016) in the two papers cited above represent a paradox related to the ontological nature of Ba. Both assert that Originating Ba can occur online without physical context since rich interactions are now possible on virtual platforms, yet the ontological perspective of Originating Ba places the physicality of interactions centre-stage. Further, a degree of confusion between the SECI model (a process) and Ba (a context) requires clarification.

Each stage of the SECI model illustrates a process of knowledge conversion which occurs within the context of $\mathrm{Ba}$. If the Socialisation process (which is part of Originating $\mathrm{Ba}$ ) can occur online, it is tempting to conclude that the same also applies to Originating $\mathrm{Ba}$. Here lies the paradox. This conclusion contradicts the ontological foundation of Originating $\mathrm{Ba}$, which is defined by physical face-to-face interactions. Only in physical space can the complexity of physical senses and psycho-emotional characteristics of human beings be grasped (Nonaka et al, 2000). In addition, Originating $\mathrm{Ba}$ is also characterised by a 'here and now' quality. This implies that only synchronous and dialectical interactions can occur within this space. Thus it might be argued that the study of blogs conducted by Martin-Niemi and Greatbanks (2010) was executed partly on the basis on a misassumption (in respect of Originating $\mathrm{Ba}$ ) since blog interactions are often asynchronous. Similarly, Bartolacci et al. (2016) emphasise the ability of users of the platform that they investigated to 'see' each other (without specifying whether the visual contact that they report included live interactions akin to online video conferencing). The 


\section{Buunk, I., Smith C.F., \& Hall, H. (2018 in press). Tacit knowledge sharing in online environments: locating 'Ba' within a platform for public sector professionals. Journal of Librarianship and Information Science.}

implication here is that technology offers proxies for the physical and spatial elements associated with Originating $\mathrm{Ba}$, again representing a challenge to the ontological foundations of this type of $\mathrm{Ba}$. From the analysis presented here it is clear that further empirical study is required to more fully investigate assertions that Originating Ba can occur online.

\section{Social media affordances}

Given the potential power ascribed to social media as an agent of knowledge transfer, further consideration must be given to the potential affordances that social media presents in organisational settings. Panahi et al. (2013) argue that social media can facilitate the sharing of tacit knowledge by (1) initiating informal discussions among experts; (2) fostering collective intelligence (providing a virtual, participatory and collaborative space to create new knowledge); (3) making tacit and personal knowledge visible and accessible; and (4) decreasing the time and the effort needed for sharing knowledge online. These four themes are also addressed by other researchers, as illustrated in the examples below.

For example, Jalonen (2014) argues that social media can help employees become involved in informal discussions within their organisation. These discussions matter as they integrate the 'human factor' into the process of articulating problems and finding solutions (Boddy et al. 2005). This is confirmed in a study in which it is demonstrated that both blogs and wikis capture unstructured information and make it available to organisational team members in an efficient way (Chirumalla, 2013). Similar claims are made for social media in respect of workplace learning in cases when employees seek answers to their questions in online communities (Thomas and Akdere, 2013).

The deployment of social media tools to enhance the generation of organisational collective intelligence by connecting up that of individuals is discussed by Razmerita et al (2014). This happens when individuals contribute collectively to generate useful content, for example when a group works together to solve a problem raised by a single individual (Jalonen, 2014).

Whether knowledge is personal or collective, it may be rendered visible by social media (Jalonen, 2014). This occurs when knowledge is shared (as information) in online social interactions (Razmerita et al., 2014). Perhaps of greater significance is that social media provide opportunities for individual employees to expose their skills, thus laying routes for others to access their tacit knowledge, as illustrated by Buunk et al. (2017) and Leonardi and Meyer (2015).

The fourth affordance of social media proposed by Panahi (2013) relates to the argument that tacit knowledge is difficult to share using technological means (in general) (for example, Haldin-Herrgard, 2000). However, (newer) social media are perceived as easy to use (Hsu and Lin, 2008; Chen and Bryer, 2012). If only a small amount of effort is 


\section{Buunk, I., Smith C.F., \& Hall, H. (2018 in press). Tacit knowledge sharing in online environments: locating 'Ba' within a platform for public sector professionals. Journal of Librarianship and Information Science.}

needed to learn how to deploy these technologies, then this decreases the time and effort needed to share knowledge online (Gordeyeva, 2010).

\section{Social media as tools for knowledge sharing in the public sector: the research opportunity}

The review of the literature as presented above exposes a number of opportunities to extend understandings of knowledge sharing practice in online environments. The question of $\mathrm{Ba}$ as originally conceived is of particular interest two decades since its introduction now that online social platforms (unavailable in the mid-1990s) are embedded in large organisations. An investigation into these themes in the context of the public sector was an attractive proposition because such a study would respond to calls to develop the research agenda in a context that is often overlooked by knowledge management researchers (as noted, for example, by Massaro et al (2015)).

Meeting these goals was achieved through the collection of data from members of an online social platform for UK public sector workers. It was anticipated that the findings to emerge from the analysis of this data would challenge and extend existing theoretical perspectives on tacit knowledge sharing, and in particular address questions around the nature of $\mathrm{Ba}$ on technology platforms designed for collaborative problem solving across distributed groups.

\section{Research design}

The site identified for data collection for this study was Knowledge Hub (KHub). KHub is the UK's largest cross-organisational public sector online collaboration platform. It provides access to forums, groups (opened, restricted or private), blogs, wiki, and instant messaging features. There is also a 'library' on KHub that is used by its members to upload and share documents. These facilities are offered free of charge to support knowledge sharing amongst public sector workers - as individuals and as communities of practice - with the ultimate goal of promoting continuous improvement in UK public services delivery. The majority of KHub's membership belongs to public and third sector organisations such as national and local government, social services, and charities. They work across a wide range of sectors such as health, education, housing, and the emergency services. The scope and reach of KHub across the public sector led to its selection as the site for data collection for this study.

To access a manageable amount of data for analysis, the decision was taken to survey a section of the KHub membership. Given the location of the research team, a survey of members of KHub active in Scotland was deemed appropriate. This population comprises approximately 17,000 individuals, of which about a quarter (around 4,250) are contributing users. 


\section{Buunk, I., Smith C.F., \& Hall, H. (2018 in press). Tacit knowledge sharing in online environments: locating 'Ba' within a platform for public sector professionals. Journal of Librarianship and Information Science.}

Access to KHub community targeted for the study was facilitated through the Improvement Service. Publicly funded, the Improvement Service is the national improvement organisation for local government in Scotland. Amongst the range of products and advisory services it provides are consultation and facilitation, training, performance management and improvement, and research. KHub is a significant element of that work, and, in Scotland, the Improvement Service is responsible for the delivery of this online social platform.

A collaborative approach to the research design resulted in the decision to build the survey using the Improvement Service's licensed Smart Survey software. Smart Survey is regularly used by the Improvement Service for on-going engagement work with the KHub community, and thus the membership is familiar with its look and feel. While the presentation of the survey made it obvious that it was disseminated by the Improvement Service, the academic credentials of the study were emphasised in the invitation to complete it. This was to ensure that the participants understood the academic nature of the work. The survey questions were designed on the basis of findings from a large review of the literature (covering themes of knowledge ontologies, models of knowledge sharing, applications of social media for knowledge sharing, and knowledge management in the public sector) and in consultation with key stakeholders at the Improvement Service.

The survey questions were set out in the form of statements, to which participants were invited to score extent of agreement on a Likert scale. For instance, respondents were asked to indicate their level of agreement with the following statement: 'KHub helps me to do my work with more efficiency'. Matrix-type questions were also used to gather additional detail. Here respondents were invited to indicate the tools and/or services that they use on KHub (for example, messaging, wiki, forums) and their purpose (for example, to develop learning, or request help).

The survey was live for six weeks between 11th July and 26th August 2016. A total of 1,062 KHub members active on the platform's Scottish section responded, the majority of whom were also based in Scotland. This figure represents approximately $25 \%$ of the contributing membership, and $6 \%$ of the population as a whole.

The survey responses were analysed to explore the place of KHub in the participants' information landscape, and the affordances offered by social media therein. In addition, indicative demographic data provided by the respondents was useful for profiling the user population. Descriptive statistical analysis of responses to a sub-set of the survey questions surfaced the main findings reported in this article. This selective approach brings benefits of a clear and straightforward report, and also aids transparency in the interpretation of the data of significance to the research themes discussed. 


\section{Findings}

The findings are reported with reference to two themes. First, findings on online social interactions as related to tacit knowledge sharing are presented. This is done with reference to four outcomes: (1) learning; (2) expertise sharing; (3) problem solving, and (4) innovating. These activities belong to the technical dimension of tacit knowledge, understood as that which cannot be codified (Nonaka, 1994). The ways in which these findings relate to types of $\mathrm{Ba}$ is also assessed. Second, the specific technical affordances for tacit knowledge sharing as enabled by the online social platform are explored. Here are examined the extent to which the platform: (1) allows the initiation of informal and professional discussions; (2) fosters collective intelligence; (3) increases the visibility and accessibility of tacit and personal knowledge; and (4) has an impact on the investment in time and effort required for knowledge sharing.

\section{Online Social interactions}

Table 1 summarises the level of agreement/disagreement with statements in the survey related to social interactions. These responses are explored in more detail below.

\begin{tabular}{|c|c|c|}
\hline $\begin{array}{l}\text { On Knowledge Hub I } \\
\text { find it easy to... }\end{array}$ & $\begin{array}{l}\text { Total percentage agreed } \\
\text { or strongly agreed }\end{array}$ & $\begin{array}{l}\text { Total percentage disagreed } \\
\text { or strongly disagreed }\end{array}$ \\
\hline ...develop my learning & $58.0 \%$ & $12.0 \%$ \\
\hline $\begin{array}{l}\text {...share my knowledge } \\
\text { and expertise }\end{array}$ & $58.4 \%$ & $10.5 \%$ \\
\hline $\begin{array}{l}\text {...request help from } \\
\text { others }\end{array}$ & $63.2 \%$ & $9.7 \%$ \\
\hline $\begin{array}{l}\text {...help others to solve } \\
\text { their problems }\end{array}$ & $52.9 \%$ & $8.8 \%$ \\
\hline ...discover new ideas & $52.2 \%$ & $13.8 \%$ \\
\hline
\end{tabular}

Table 1: overview of main findings on social interactions

Learning

- More than half of the respondents agreed (49\%) or strongly agreed (9\%) with the statement 'On Knowledge Hub I find it easy to develop my learning'. 
Buunk, I., Smith C.F., \& Hall, H. (2018 in press). Tacit knowledge sharing in online environments: locating 'Ba' within a platform for public sector professionals. Journal of Librarianship and Information Science.

- A small percentage of the respondents (12\%) disagreed (9\%) or strongly disagreed (3\%) with the statement 'On Knowledge Hub I find it easy to develop my learning'

The analysis of these data reveals that the online social platform supports learning. Taking into account prior research (for example, Boh, 2007) it is likely in this case that that individual learning occurs when workers create new ideas or innovate, drawing on prior experience, and team learning occurs when individuals participate in group interactions around shared problems or issues, or when individuals from a group decide to discuss and solve commonly shared issues together. In respect of $\mathrm{Ba}$, the agreement with this statement on learning is redolent of Exercising Ba because individuals use KHub as a source of practitioner insight than may lead to action. An important caveat, however, is that Exercising Ba has a focus on knowledge-by-doing: whether or not an online system such as KHub could support a full implementation of 'doing' is debatable.

\section{Expertise sharing}

- Over half the respondents agreed $(51.1 \%)$ or strongly agreed $(7.3 \%)$ with the statement 'On Knowledge Hub I find it easy to share my knowledge and expertise'.

- A small percentage of the respondents (10.5\%) disagreed (7.6\%) or strongly disagreed $(2.9 \%)$ with the statement 'On Knowledge Hub I find it easy to share my knowledge and expertise'.

That KHub has a role in enabling users to share knowledge and expertise is evident through the responses noted above. This finding lends further support to the argument that social media affordances facilitate the sharing of knowledge and expertise, as advocated, for example, by Panahi (2012). The coming together of experts online to share their knowledge and expertise be externalising it on KHub has a marked alignment with the Dialoguing/interacting Ba.

\section{Problem solving}

- Almost two thirds (63.2\%) of the respondents agreed (51.1\%) or strongly agreed $(12.1 \%)$ with the statement 'On Knowledge Hub I find it easy to request help from others'

- A small percentage of the respondents disagreed (6.9\%) or strongly disagreed $(2.8 \%)$ with the statement 'On Knowledge Hub I find it easy to request help from others'

- Over half $(52.9 \%)$ the respondents agreed (46.6\%) or strongly agreed (6.3\%) with the statement 'On Knowledge Hub I find it easy to help others to solve their problems'

- A small percentage of the respondents disagreed (6.3\%) or strongly disagreed $(2.5 \%)$ with the statement 'On Knowledge Hub I find it easy to help others to solve their problems' 
Responses to two of the statements in the survey as noted above demonstrate the clear utility of the KHub platform for problem solving. These social interactions around deliberately offering and giving help correspond to Dialoguing/interacting Ba. Here dialogue is fundamental to the processes of externalisation and sharing/contrasting of mental models and skills.

\section{Innovating}

- Over half $(52.2 \%)$ the respondents agreed (44.7\%) or strongly agreed (7.5\%) with the statement 'On Knowledge Hub I find it easy to discover new ideas'.

- A small percentage of the respondents disagreed (10.7\%) and strongly disagreed $(3.1 \%)$ with the statement 'On Knowledge Hub I find it easy to discover new ideas'.

Here there is evidence that the sharing of knowledge on an online social platform can foster innovation. Again, there is a correlation here between the Dialoguing/interacting $\mathrm{Ba}$ where the sharing of know-how enables innovation in thinking, and may subsequently result in action.

Taken together, these findings on the building of knowledge through social interactions in the context of commonly shared problems have links with other similar work concerned with communities of practice (for example, Hall and Graham 2004; Annabi and McGann, 2013). Here the social interactions represent a form of infrastructure for processes such as learning as previously noted in the extant literature (for example, Haghshenas et al., 2014; Ryan and O’Connor, 2013).

Furthermore, the findings on social interactions, drawn from responses to five of the statements in the survey as presented here, suggest a mapping between four outcomes and two types of Ba. These are summarised in Figure 3 below.

\begin{tabular}{|lll|}
\hline Learning & $\rightarrow$ & Exercising Ba \\
\hline $\begin{array}{l}\text { Expertise sharing } \\
\text { Problem solving } \\
\text { Innovating }\end{array}$ & $\rightarrow$ & Dialoguing/interacting Ba \\
\hline
\end{tabular}

Figure 3: Four outcomes of social interactions on KHub and two types of Ba

\section{Affordances of the online social platform for tacit knowledge sharing}

Table 2 summarises the level of agreement/disagreement with statements in the survey on the affordances of the online social platform for tacit knowledge sharing. These responses are explored in more detail below. 
Buunk, I., Smith C.F., \& Hall, H. (2018 in press). Tacit knowledge sharing in online environments: locating 'Ba' within a platform for public sector professionals. Journal of Librarianship and Information Science.

\begin{tabular}{|l|c|c|}
\hline $\begin{array}{l}\text { Knowledge Hub has } \\
\text { allowed me to... }\end{array}$ & $\begin{array}{c}\text { Total percentage agreed } \\
\text { or strongly agreed }\end{array}$ & $\begin{array}{c}\text { Total percentage disagreed } \\
\text { or strongly disagreed }\end{array}$ \\
\hline $\begin{array}{l}\text {... have informal } \\
\text { discussions }\end{array}$ & $49.4 \%$ & $14.3 \%$ \\
\hline $\begin{array}{l}\text {... discuss professional } \\
\text { issues }\end{array}$ & $64.8 \%$ & $10.5 \%$ \\
\hline ... expand my network & $60.5 \%$ & $11.6 \%$ \\
\hline ... save time at work & $30.4 \%$ & $23.7 \%$ \\
\hline
\end{tabular}

Initiation of informal and professional discussions

- Almost half (49.4\%) the respondents agreed (43.9\%) or strongly agreed $(5.5 \%)$ with the statement 'Knowledge Hub has allowed me to have informal discussions'.

- A small percentage of the respondents (14.3\%) disagreed (11.2\%) or strongly disagreed (3.1\%) with the statement 'Knowledge Hub has allowed me to have informal discussions'.

- Almost two-thirds $(64.8 \%)$ of the respondents agreed $(10.7 \%)$ or strongly agreed $(54.1 \%)$ with the statement 'Knowledge hub has allowed me to discuss professional issues'.

- A small percentage of the respondents (10.5\%) disagreed $(7.5 \%)$ or disagreed strongly (3\%) with the statement 'Knowledge hub has allowed me to discuss professional issues'.

The analysis of survey data on informal and professional discussions shows that these are supported on KHub. This finding aligns with similar conclusions on the value of online social platforms for tacit knowledge sharing drawn by Panahi et al., (2013).

\section{Fostering collective intelligence}

Collective intelligence emerges when individuals work collectively to find solutions. Of relevance to this theme are the findings related to the offering and receiving of help, as summarised with reference to problem solving above. From these it can be concluded that KHub plays a part in fostering collective intelligence. However, when respondents were asked about their preferred way of requesting help from others, email was placed at the top of the ranking. In second place was 'asking face-to-face'. KHub was ranked third, in the same position as 'using the phone'. This finding suggests that high-value collective intelligence may be best developed initially in one-to-one or small group settings between specific contacts (accessed more personally by email or directly face-to-face), who are 


\section{Buunk, I., Smith C.F., \& Hall, H. (2018 in press). Tacit knowledge sharing in online environments: locating 'Ba' within a platform for public sector professionals. Journal of Librarianship and Information Science.}

known to have specific knowledge to share. Thus, this affordance of the online social platform for tacit knowledge sharing is limited.

Visibility and accessibility of tacit and personal knowledge

- Almost two-thirds $(60.5 \%)$ of the respondents agreed $(10.8 \%)$ or strongly agreed $(49.7 \%)$ with the statement 'KHub has allowed me to expand my network'.

- A small percentage (11.6\%) disagreed (9\%) or strongly disagreed (2.6\%) with the statement 'KHub has allowed me to expand my network'.

The analysis of these data suggests that online social platforms can widen networks with the potential for opening up opportunities for collaboration and access to new resources. The finding on this affordance of KHub adds to prior work on 'knowledge awareness' as related to the visibility of individuals' competencies, for example in profile listings (Cooke and Hall, 2013) and observations of their interactions online (Leonardi and Meyer, 2015).

Investment in time and effort for knowledge sharing

- Less than a third (30.4\%) agreed (25.3\%) or strongly agreed $(5.1 \%)$ with the statement 'Knowledge Hub has allowed me to save time at work'.

- Almost one quarter (23.7\%) disagreed (18.6\%) or strongly disagreed (5.1\%) with the statement 'Knowledge Hub has allowed me to save time at work'.

- The majority of respondents (42.9\%) neither agreed nor disagreed with the statement 'Knowledge Hub has allowed me to save time at work'.

These findings on the perceived value (or not) of the online social platform in saving time and effort for knowledge sharing are significant, especially since they contradict the findings of prior work (for example, Ciabuschi, 2005; Haas and Hansen, 2007).

\section{Discussion}

The results presented here correlate with the majority of arguments made by Panahi et al (2013) and others (for example, Nilmanat, 2009; Murphy and Salomone, 2013) that online social platforms are facilitators of tacit knowledge sharing, particularly in respect of initiating informal and professional discussions, and increasing the visibility and accessibility of tacit and personal knowledge. The findings from this study also indicate that online social platforms have a role to play in the fostering of collective intelligence, although this role is weaker than the others. In one important respect, however, the results of this study are less positive than those reported in prior work (for example, Ciabuschi, 2005; Haas and Hansen, 2007): as far as saving time and effort required for knowledge sharing is concerned, the respondents doubted the value of the online social platform. This question merits additional scrutiny and will be investigated further as part of the larger study that incorporates the work presented here. 


\section{Buunk, I., Smith C.F., \& Hall, H. (2018 in press). Tacit knowledge sharing in online environments: locating 'Ba' within a platform for public sector professionals. Journal of Librarianship and Information Science.}

Taking into account these findings on the affordances of KHub, and the four broad outcomes of the social interactions supported on the system - learning, expertise sharing; problem solving, and innovating - it is possible to consider the ways in which these findings relate to Ba. In 1998 Nonaka and Konno claimed that virtual spaces such as online networks or databases could be classed as one type of Ba (only): Cyber Ba for activities such as networking, collaboration, and reaching consensus online. However, the findings from this study conducted almost two decades later, and with reference to an online social platform, indicate that two other types of Ba may also occur within a virtual space. These are Dialoguing/interacting $\mathrm{Ba}$ and Exercising $\mathrm{Ba}$.

The existence of these two other types of Ba may be accounted for by the affordances of new technologies that have been developed since the 1990s, notably those that offer the same features as mainstream social media. The evidence presented here to support this explanation builds on the work of Martin-Niemi and Greatbanks (2010) on blogging and $\mathrm{Ba}$. The findings also align with the work of others who imply that some online platforms may be considered Ba per se. This is on the basis that they represent a space (Razmerita et al., 2014), and because this space enables social interactions.

As has been noted above, others have gone as far as to argue that since all SECI phases can occur in online spaces, (whether totally or partially) then all types of Ba can be virtual (Bartolacci, et al, 2016). The findings from the study reported here (at least at this stage) do not support the suggestion that the fourth type of $\mathrm{Ba}$ - Originating $\mathrm{Ba}$ - can occur online. However, the earlier study that highlighted the occurrence of Originating $\mathrm{Ba}$ was focussed on a virtual environment in which face-to-face interactions were enabled by rich media communication tools (Bartolacci, et al, 2016). That such advanced tools have not been deployed on KHub may be the reason for the failure to identify Originating $\mathrm{Ba}$ in the context of this study. Whatever the explanation, more empirical evidence is needed to explore claims for Originated $\mathrm{Ba}$ in virtual environments, taking into account both the ontological nature of the Ba itself, and the context of the virtual environment under scrutiny.

\section{Conclusion and further work}

Two main findings emerge from the study. The first is that online social platforms play a strong role in in the facilitation of tacit knowledge sharing, and this leads to outcomes of learning, expertise sharing, problem solving, and innovating. The second is that online platforms are important to the initiation of discussions among experts, the fostering of collective intelligence, and making tacit and personal knowledge visible and accessible quickly and with minimal effort.

This work makes an important theoretical contribution by renewing consideration of Nonaka and Konno's concept of Ba (1998) - a concept is often regarded as challenging to understand from a western perspective. It does so through the identification of 


\section{Buunk, I., Smith C.F., \& Hall, H. (2018 in press). Tacit knowledge sharing in online environments: locating 'Ba' within a platform for public sector professionals. Journal of Librarianship and Information Science.}

Dialoguing/interacting $\mathrm{Ba}$ and Exercising $\mathrm{Ba}$ (in addition to Cyber $\mathrm{Ba}$ ) in a particular online environment, where social interactions are supported by tools that did not exist when Ba was first proposed in the 1990s. The findings are also of value to practitioner audiences in the field of Knowledge Management, especially those familiar with the SECI model and interested in its applicability to modern collaborative work environments.

It should be emphasised that the work reported here is limited because it is based the analysis of responses to a sub-set of questions from a larger survey. Further analysis of the full data set currently in progress, to include statistical testing, is anticipated to build on the contribution to the field made here. In addition, a second data set drawn from follow-up in-depth interviews with members of the cohort that completed the survey will extend consideration of the findings presented in this article. As such, further contributions on the themes of knowledge management and human information behaviour will be made in direct response to earlier calls for such work to inform theory development in the domain (for example, Halbwirth and Olsson, 2007).

\section{Funding}

The author(s) received no financial support for the research, authorship, and/or publication of this article. 
Buunk, I., Smith C.F., \& Hall, H. (2018 in press). Tacit knowledge sharing in online environments: locating 'Ba' within a platform for public sector professionals. Journal of

Librarianship and Information Science.

\section{References}

Annabi H and McGann ST (2013) Social media as the missing link: connecting communities of practice to business strategy. Journal of Organizational Computing and Electronic Commerce 23(1-2): 56-83.

Ardichvili A (2008) Learning and knowledge sharing in virtual communities of practice: motivators, barriers, and enablers. Advances in Developing Human Resources 10(4): $541-554$.

Bartolacci C, Isidori D, Cristalli C and Niccolini F (2016) Ba evolution: virtual spaces for inter-organizational knowledge creation. Journal of Knowledge Management 20(4): 793-811.

Boddy D, Boonstra A and Kennedy G (2005) Managing information systems: an organisational perspective. Harlow: Financial Times / Prentice Hall.

Boh WF (2007) Mechanisms for sharing knowledge in project-based organizations. Information and Organization 17(1): 27-58.

Buunk I, Hall H and Smith C (2017). Skills in sight: how social media affordances increase network awareness. In: Proceedings of the 18th European Conference on Knowledge Management ECKM 2017. Barcelona, 8-6 September 2017, pp.181-186. Reading: Academic Conferences and Publishing International Limited.

Chen B and Bryer T (2012) Investigating instructional strategies for using social media in formal and informal learning. International Review of Research in Open and Distance Learning 13(1): 87-104.

Chirumalla K (2013) Managing knowledge for product-service system innovation: the role of Web 2.0 technologies. Research-Technology Management 56(2): 45-53. 
Buunk, I., Smith C.F., \& Hall, H. (2018 in press). Tacit knowledge sharing in online environments: locating 'Ba' within a platform for public sector professionals. Journal of

Librarianship and Information Science.

Choo WC and Alvarenga NR (2010) Beyond the ba: managing enabling contexts in knowledge organizations. Journal of Knowledge Management 14(4): 592-610.

Ciabuschi F (2005) On IT systems and knowledge sharing in MNCs: a lesson from Siemens AG. Knowledge Management Research \& Practice 3(2): 87-96.

Cooke L and Hall H (2013) Facets of DREaM: a Social Network Analysis exploring network development in the UK LIS research community. Journal of Documentation 69(6): 786-806.

Edmondson AC, Winslow AB, Bohmer RMJ and Pisano GP (2003) Learning how and learning what: effects of tacit and codified knowledge on performance improvement following technology adoption. Decision Sciences 34(2): 197-223.

Giddens A (1984) The constitution of society: outline of the theory of structuration.

Berkeley and Los Angeles: University of California Press.

Hall, H. \& Goody, M. (2007). KM culture and compromise - interventions to promote knowledge sharing supported by technology in corporate environments. Journal of Information Science, 33(2), 181-188

Gordeyeva I (2010) Enterprise 2.0: theoretical foundations of social media tools influence on knowledge sharing practices in organizations. Master thesis, Department of Business Information Technology, School of Management and Governance, University of Twente, Enschede, 2010.

Haas M and Hansen T (2007) Different knowledge, different benefits: toward a productivity perspective on knowledge sharing in organizations. Strategic Management Journal 28: 1133-1153.

Haghshenas M, Sadeghzadeh A, Nassiriyar M and Shahbazi R (2014) The implementation of social media for educational objectives. The International Journal of Engineering and Science 3(12): 28-32. 
Buunk, I., Smith C.F., \& Hall, H. (2018 in press). Tacit knowledge sharing in online environments: locating 'Ba' within a platform for public sector professionals. Journal of

Librarianship and Information Science.

Halbwirth SJ and Olsson MR (2007) Working in parallel: themes in knowledge management and information behaviour. In Hawamdeh S (Ed.) Creating collaborative advantage through knowledge and innovation Singapore: World scientific pp 69-89.

Haldin-Herrgard T (2000) Difficulties in diffusion of tacit knowledge in organizations. Journal of Intellectual Capital 1(4): 357-365.

Hall H and Graham D (2004) Creation and recreation: motivating collaboration to generate knowledge capital in online communities. International Journal of Information Management 24(3): 235-246.

Hartley J (2008) The innovation landscape for public service organizations. In: Hartley J, Skelcher C, Donaldson C and Wallace M (Eds), Managing to Improve Public Services Cambridge: Cambridge University Press, 197-216.

Hartley J and Skelcher C (2008) The agenda for public service improvement. In: Hartley, J, Skelcher C, Donaldson, C and Wallace M (Eds), Managing to Improve Public Services, Cambridge: Cambridge University Press, 3-23.

Hubert C and Lopez B (2013) Breaking the barriers to knowledge sharing. American Productivity and Quality Center. Available at https://1pdf.net/download/breakingthe-barriers-to-knowledge-sharing-by-cindy-hubert-and-brittany-lopezor_590915d2f6065dc853a0c395 (Accessed 27 August 2017)

Hsu CL and Lin JCC (2008) Acceptance of blog usage: the roles of technology acceptance, social influence and knowledge sharing motivation. Information \& Management, 45(1): 65-74.

Jalonen H (2014) A framework for dealing with fundamental knowledge problems through social media. Vine 44(4): 558-578. 
Buunk, I., Smith C.F., \& Hall, H. (2018 in press). Tacit knowledge sharing in online environments: locating 'Ba' within a platform for public sector professionals. Journal of

Librarianship and Information Science.

Lave J and Wenger E Situated Learning: legitimate peripheral participation. Cambridge:

Cambridge University Press.

Leonardi PM and Meyer SR (2015) Social media as social lubricant: how ambient awareness eases knowledge transfer. American Behavioral Scientist (59)1: 10-34.

Levenberg A and Caspi A (2010) Comparing perceived formal and informal learning in face-to-face versus online environments. Interdisciplinary Journal of E-learning and Learning Objects 6: 323-333.

Massaro M, Dumay J and Garlatti A. (2015) Public sector knowledge management: a structured literature review. Journal of Knowledge Management 19(3), 530-558.

Martin-Niemi F and Greatbanks R (2010) The ba of blogs: enabling conditions for knowledge conversion in blog communities. Vine 40(1): 7-23.

Mcdermott R and O’Dell C (2001) Overcoming cultural barriers to sharing knowledge. Journal of Knowledge Management 5(1): 76-85.

McMillan DW and Chavis DM (1986). Sense of community: a definition and theory. Journal of Community Psychology 14(1):6-23.

Mills LA, Knezek G and Khaddage F (2014) Information seeking, information sharing, and going mobile: three bridges to informal learning. Computers in Human Behavior 32: $324-334$.

Murphy G and Salomone S (2013) Using social media to facilitate knowledge transfer in complex engineering environments: a primer for educators. European Journal of Engineering Education 38(1): 70-84.

Nakamori Y (2006) Designing, utilizing and evaluating technology-creating Ba' in a Japanese scientific research institution. Systems Research and Behavioral Science 23(1): 3-19. 
Buunk, I., Smith C.F., \& Hall, H. (2018 in press). Tacit knowledge sharing in online environments: locating 'Ba' within a platform for public sector professionals. Journal of

Librarianship and Information Science.

Nilmanat R. (2009) Image usage and tacit knowledge sharing in online communities. In: International Conference on Computing in Engineering, Science and Information ICC 2009, pp 343-346.

Nonaka I (1994) A dynamic theory knowledge of organizational creation. Organization Science 5(1): 14-37.

Nonaka I and Konno N (1998) The concept of "Ba": building a foundation for knowledge creation. California Management Review 40(3): 40-54.

Nonaka I and Toyama R (2003) The knowledge-creating theory revisited: knowledge creation as a synthesizing process. Knowledge Management Research \& Practice (1) $1: 2-1$

Oguz F and Sengün AE (2011) Mystery of the unknown: revisiting tacit knowledge in the organizational literature. Journal of Knowledge Management 15(3): 445-461.

Panahi S, Watson J and Partridge H (2013) Towards tacit knowledge sharing over social web tools. Journal of Knowledge Management 17(3): 379-397.

Pettigrew A (2005) The character and significance of management research on the public services. Academy of Management Journal 48(6): 973-977.

Rashman L, Withers E and Hartley J (2009) Organizational learning and knowledge in public service organizations: a systematic review of the literature. International Journal of Management Reviews 11(4): 463-494.

Razmerita L, Kirchner K and Nabeth T (2014) Social media in organizations: leveraging personal and collective knowledge processes. Journal of Organizational Computing and Electronic Commerce 24(1): 74-93.

Rosen B, Furst S and Blackburn R (2007) Overcoming barriers to knowledge sharing in virtual teams. Organizational Dynamics 36(3): 259-273. 
Buunk, I., Smith C.F., \& Hall, H. (2018 in press). Tacit knowledge sharing in online environments: locating 'Ba' within a platform for public sector professionals. Journal of

Librarianship and Information Science.

Ryan S and O'Connor RV (2013) Acquiring and sharing tacit knowledge in software development teams: an empirical study. Information and Software Technology 55(9): $1614-1624$.

Thomas KJ and Akdere M (2013). Social media as collaborative media in workplace learning. Human Resource Development Review 12(3): 329-344.

Widen-Wulff G, Ek S, Ginman M, Perttila R, Sodergard P and Totterman AK (2008)

Information behaviour meets social capital: a conceptual model. Journal of Information Science 34(3): 346-355.

Wilson S and Lilly A (2016) Knowledge Hub: case study. Institute for Government report: $1-9$

Zhu Z (2006) Nonaka meets Giddens: a critique. Knowledge Management Research \& Practice 4(2): 106-115. 